\title{
Teachers' teaching practices and beliefs regarding context-based tasks and their relation with students' difficulties in solving these tasks
}

\author{
Ariyadi Wijaya ${ }^{1,3}$ - Marja van den Heuvel-Panhuizen ${ }^{1,2}$. \\ Michiel Doorman ${ }^{1}$
}

Received: 9 April 2014 /Revised: 16 August 2015 /Accepted: 19 October 2015 /

Published online: 11 November 2015

(C) Mathematics Education Research Group of Australasia, Inc. 2015

\begin{abstract}
In this study, we investigated teachers' teaching practices and their underlying beliefs regarding context-based tasks to find a possible explanation for students' difficulties with these tasks. The research started by surveying 27 Junior High School teachers from seven schools in Indonesia through a written questionnaire. Then, to further examine teachers' teaching practices related to context-based tasks, four teachers were observed and video recorded in two mathematics lessons in which they were asked to deal with context-based tasks. The questionnaire data revealed that the teachers had a tendency toward a view on teaching and learning mathematics which includes encouraging students to be actively involved in solving problems in various contexts. Although this finding suggests that the teachers may offer opportunities to learn context-based tasks to students, the questionnaire data also revealed that the teachers saw context-based tasks as plain word problems. Furthermore, the observations disclosed that their teaching was mainly teacher-centered and directive, which is not considered to be supportive for learning to solve context-based tasks. Combining the findings of this study with the results from our earlier study on Indonesian students' errors when solving context-based tasks, we found a relationship between how Indonesian teachers teach context-based tasks and the errors Indonesian students make in solving these tasks. These findings support the conclusion that insufficient
\end{abstract}

Ariyadi Wijaya

a.wijaya@staff.uny.ac.id

1 Freudenthal Institute for Science and Mathematics Education (FIsme), Utrecht University, Princetonplein 5, 3508 AD Utrecht, The Netherlands

2 Faculty of Social and Behavioural Sciences, Utrecht University, Heidelberglaan 1, 3584 CS Utrecht, The Netherlands

3 Mathematics Education Department - FMIPA, Yogyakarta State University, Kampus Karangmalang, Yogyakarta 55281, Indonesia 
opportunity-to-learn to solve context-based tasks offered by teachers is a possible explanation for students' difficulties in solving these tasks.

Keywords Context-based tasks · Students' difficulties · Teachers' beliefs · Teachers' teaching practices

\section{Introduction}

Currently, the ability to solve context-based mathematics tasks is considered a core goal of mathematics education all around the world (see, e.g., Eurydice 2011; Graumann 2011; NCTM 2000). However, despite the significance attributed to this ability, several studies revealed that students have low performance on such tasks (Cooper and Dunne 2000; Sam et al. 2001). For example, the PISA 2012 study (OECD 2013) showed that about $32 \%$ of the total group of students in the 65 participating countries had a performance below the baseline level of mathematical literacy, i.e., the Level 2 , and could only answer "questions involving familiar contexts where all relevant information is present and the questions are clearly defined" (OECD 2013, p. 61). Furthermore, in 15 countries in this PISA study, more than half the students performed below this level. More particularly, with respect to students' difficulties when solving context-based tasks, various studies showed that students have problems with understanding the wording of context-based tasks and identifying relevant information (Prakitipong and Nakamura 2006). Also, it was found that students struggle to select adequate mathematical procedures (Clements 1980) and often just apply a routine procedure without taking realistic considerations into account (Sepeng 2013; Verschaffel et al. 2000; Xin et al. 2007). In addition, some other studies (e.g., Cooper and Dunne 2000; Gellert and Jablonka 2009) showed that students can also take too much account of the context of the problem.

Indonesia, like many other countries, attaches high value to the use of context-based mathematics tasks (Pusat Kurikulum 2003). Nevertheless, the PISA results repeatedly showed that Indonesian students perform low in solving context-based tasks. For example, in the PISA 2009 study (OECD 2010), $77 \%$ of Indonesian students did not reach Level 2. Therefore, the result from this PISA study prompted us to set up a project called "Context-based Mathematics Tasks Indonesia" (CoMTI) to investigate how Indonesian students' performance can be improved. In this project, context-based tasks were considered as tasks that are situated in real-world settings and that provide elements or information that need to be organized and modeled mathematically. Although various operationalizations of such tasks are possible, we based our study on the context-based tasks as used in PISA, because then our study could contribute to gaining knowledge about how the performance of Indonesian students in international comparisons such as PISA can be improved.

The first step in the CoMTI project was investigating Indonesian students' difficulties when solving context-based tasks. It was found that the students mostly got stuck in the early stages of the solving process, i.e., they had particular difficulties with comprehending a context-based problem and transforming a context-based problem into a mathematical problem (Wijaya et al. 2014). The next step in the CoMTI project was finding possible causes of these difficulties. For this, the concept of opportunity-tolearn (OTL) was taken into account because it is a crucial aspect in investigating 
possible reasons for students' low performance (Brewer and Stasz 1996; Hiebert and Grouws 2007). Our first focus was on the OTL offered by textbooks. An analysis of Indonesian mathematics textbooks revealed that only $11 \%$ of tasks were context-based (Wijaya et al. 2015).

Although this low percentage of context-based tasks in textbooks gave us a possible explanation for Indonesian students' low scores on these tasks, it might not be the only reason for the low scores, because students' performance can also be influenced by teachers' teaching practices (Grouws and Cebulla 2000; Hiebert and Grouws 2007). In other words, the teaching practice of teachers can also contribute to the students' OTL. Moreover, teachers' beliefs may also play a role in the OTL offered by teachers because teaching practice is often affected by what teachers think about the teaching and learning of mathematics (Ernest 1989; Stipek et al. 2001; Wilkins 2008). Therefore, to further investigate the OTL to solve context-based tasks given to students, the present study addressed teachers' teaching practices in relation with teachers' beliefs. In addition, we analyzed whether our findings regarding the OTL offered by Indonesian teachers correspond to the kinds of errors that Indonesian students make when solving context-based tasks.

\section{Theoretical background}

\section{OTL offered by teachers}

The so-called OTL is widely considered an important predictor of student achievement (National Research Council 2001). In international comparative studies, this concept emerged in searching for an explanation for the differences in students' mathematics performance in different countries (see e.g., Husén 1967; Valverde et al. 2002). In the First International Mathematics Study, OTL was defined as "whether or not [...] students have had the opportunity to study a particular topic or learn how to solve a particular type of problem" (Husén 1967, p. 162-163). Later, this definition was specified by Brewer and Stasz (1996), who distinguished three aspects of OTL. The first is the curriculum content which focuses on the scope of the topics offered to students. The second refers to the teaching strategies teachers use to present the topics and engage students. The third aspect concerns the instructional resources, for instance textbooks used to teach the students.

Indeed, several studies (e.g., Husén 1967; Tornroos 2005) have found that curriculum and instructional materials are important for students' OTL. Yet, there were also studies (e.g., Grouws and Cebulla 2000; Hiebert and Grouws 2007) which revealed that students' mathematical performance is largely influenced by teachers' teaching practices. These studies showed that the strategies used by teachers to teach particular topics, the kinds of tasks they presented to students, and the nature of the discussions they organized in class are important factors influencing students' OTL.

\section{Teaching practices contributing to students' OTL to solve context-based tasks}

Learning to solve context-based tasks has commonalities with the learning of mathematical modeling, especially with respect to learning to understand contextual problems 
and to identify the mathematics needed for modeling and solving these problems. Antonius et al. (2007, p. 295) argued that the learning of modeling requires more than an "explanation-example-exercise ritual," i.e., the teacher explains a concept, gives an example of a problem in which this concept is applied and finally offers the students some exercises for practicing problems with this concept. Such a directive approach does not offer students the opportunity to develop strategic competences which are necessary to solve mathematical problems in real-world settings (Antonius et al. 2007). These competences involve comprehending the problem and selecting relevant information, identifying and applying appropriate mathematical procedures, connecting different representations or mathematics concepts, and interpreting solutions (Blum 2011; OECD 2003). To achieve these competences, several authors (Antonius et al. 2007; Barnes 2000; Forman and Steen 2001) emphasized that teachers, instead of using a directive teaching method, should use a student-centered and investigative teaching approach in which students are actively involved and have the chance to struggle with a problem, and the teacher's role is consultative rather than directive. Similarly, Blum (2011, p. 25) and Blum and Ferri (2009) pleaded for consultative teaching, which is called "operative-strategic teaching," that emphasizes guiding students to actively and independently construct new knowledge by using their prior knowledge and experiences. Blum's studies showed that students who learned through such a teaching approach made more progress on their modeling competence in comparison to students who were taught according to a directive teaching approach.

A key aspect of a consultative teaching approach is that teachers should keep a balance between providing guidance and fostering students' independence by using flexible interventions and metacognitive prompts to elicit students to reflect on their own understanding of the problem and on how they selected the mathematical procedures to solve the problem. Promoting students to reflect can also be done by providing them with opportunities to assess and (if necessary) revise their own work (Bell and Pape 2012).

Further specific recommendations can be given when zooming in on the process of solving context-based tasks. This is a complex process in which students pass through several stages, including the stage of comprehension, transformation, mathematical processing, and encoding. These four stages were derived by aligning the modeling stages of Blum and Leiss (2007), the PISA levels of mathematization (OECD 2003) and the Newman's (1977) error categories (for an extended description of these stages, see Wijaya et al. 2014). They are also in agreement with the steps that Blum (2011) and Blum and Ferri (2009) identified in their so-called solution plan for modeling tasks, namely understanding the task, searching for mathematics, using mathematics, and explaining the result(s). Each of the four abovementioned stages in solving contextbased tasks can ask for specific OTL offered by teachers, as we will describe in the next sections.

\section{OTL connected to the comprehension stage}

In the comprehension stage, students have to figure out what the problem is about and identify the information that is relevant to solving it. Directly telling students what a context-based task means and what information is required is, according to Barnes (2000, p. 41), not supportive for their learning because such practice causes students to 
"have less need to struggle and less occasion to make efforts of their own to achieve understanding."

Several studies (e.g., Hagaman et al. 2012; Karbalei and Amoli 2011) have shown that the so-called three-step Read-Ask-Paraphrase (RAP) strategy can stimulate students' active involvement in getting to know what is asked in the problem and can improve reading comprehension. The first step of this RAP strategy is in agreement with the suggestion of Blum's (2011, p. 24) to ask students to "read the text precisely and imagine the situation clearly." In the second RAP step, students are encouraged to figure out what the problem is really asking them. This approach is similar to the suggestion of Kramarski et al. (2002, p. 228) to train students to formulate and answer self-addressed metacognitive comprehension questions such as "what is the problem about?" The last RAP step implies the teacher should ask students to formulate the problem in their own words. Paraphrasing is helpful for students because it makes problems more familiar and, consequently, more understandable for them (Karbalei and Amoli 2011; Kletzien 2009).

Another important aspect of comprehending a problem is awareness of the information needed to solve the problem. To achieve this, several authors (Blum 2011; Forman and Steen 2001; Lingefjärd and Meier 2010) suggested letting students discuss the information presented in a problem in relation to what is asked in the problem. Other approaches are asking students to figure out whether particular information is missing (Forman and Steen 2001) or to formulate a self-addressed question like "Do I already have enough information to solve the problem?"

\section{OTL connected to the transformation stage}

In the transformation stage, students have to transform a context-based task into a mathematical problem. Again, directly telling the students what to do might not offer them an OTL. It is more helpful when students are involved in this process and can themselves explore different ways of transforming a context-based task into a mathematical problem which they can use to solve this task. To stimulate this exploration, students can be asked to formulate and answer questions such as "What might be a possible mathematical procedure to solve this problem?" Another approach to achieve this exploration is to call up earlier experiences of the students when solving similar context-based tasks. In line with this, Kramarski et al. (2002, p. 228) suggested that teachers should encourage students to formulate and answer self-addressed questions such as "What are the similarities or differences between this problem and the problems I have ever solved?" What all these approaches have in common is that OTL in the transformation stage needs to orient students toward identifying relevant mathematical procedures for solving the problem (Galbraith and Stillman 2006).

\section{OTL connected to the mathematical processing stage}

In the mathematical processing stage, students do not in fact have to deal with the context-based character of a problem, but only carry out the mathematical procedure(s) resulting from transforming a context-based problem into a mathematical problem. Therefore, it is not surprising that for the mathematical processing stage, none of the 
aforementioned studies - e.g., Forman and Steen (2001); Kramarski et al. (2002); Lingefjärd and Meier (2010)_gave suggestions that offer students OTL. Furthermore, the mathematical processing stage can cover various mathematics topics which might make it difficult to provide a fixed suggestion or direction. Nevertheless, having fewer mistakes in performing mathematical procedures would eventually also help students to become better in solving context-based tasks. Therefore, a teaching practice in which the teacher stimulates students to check their mathematical procedures can also be considered an OTL to solve context-based tasks.

\section{OTL connected to the encoding stage}

In the encoding stage, students have to interpret a mathematical solution in terms of the situation of the context-based task and take realistic and critical considerations into account. For this, the students should be encouraged to link their solution to the situation of the task and to verify the reasonableness of the solution (Blum 2011; Forman and Steen 2001). Kramarski et al. (2002, p. 228) proposed that teachers should stimulate their students to ask themselves whether the solution makes sense. Such a teaching practice contrasts with just focusing on the correctness of the mathematical solution.

\section{Teacher beliefs contributing to Students' OTL to solve context-based tasks}

Several studies (Beswick 2005; Ernest 1989; Stipek et al. 2001; Wilkins 2008) showed the influence of teachers' beliefs on teachers' practice. For example, Beswick found a relation between teachers' positive beliefs toward the importance of problem solving in mathematics and their constructivist teaching practice in which students are actively involved in the teaching-learning process. Similarly, Chapman (2009) reported the relation between teachers' conceptions on contextbased tasks and how teachers use such tasks in their teaching. Teachers who are mostly oriented toward mathematics as computational and algorithmic problem solving conceptualize context-based tasks as word problems meant to practice earlier learned procedures. This way of teaching mathematics is quite similar to the so-called "mechanistic" approach to mathematics education as described by Treffers (1987; see also Van den Heuvel-Panhuizen 2010). In mechanistic mathematics education, the focus is mainly on bare tasks which have to be solved by performing standard procedures demonstrated by the teacher and the application of mathematics in word problems is in the final stage of learning these procedures. Characteristic for mechanistic mathematics education is a rule-governed approach to teaching word problems. The teaching focuses on exercising mathematical procedures without connection to the context of the problem. Also, according to Chapman (2009), these teachers prefer context-based tasks which have a clear question, contain only the information that is relevant for solving the task, and have an explicit suggestion about the mathematical procedure to use.

A different conception on context-based tasks is reflected by teachers who use contexts which have realistic value to students. This view on teaching mathematics and connecting mathematics and the learning of it to real-life situations is characteristic for the so-called "realistic" approach to mathematics education (Treffers 
1987; Van den Heuvel-Panhuizen 2010; Van den Heuvel-Panhuizen and Drijvers 2014). As it was found by Chapman (2009, p. 232), teachers with such a view on context-based tasks use the tasks as a tool to help students "experience the world" and develop in-depth mathematical thinking. These teachers favor context-based tasks that offer various opportunities for students to create models to structure the problems, to explore and connect different mathematical procedures or concepts, and to select information. In line with this, the teachers in Chapman's study (2009) emphasized that students can play with a large amount of information, which is also in agreement with Verschaffel et al. (2010), who pointed out that context-based tasks which do not include irrelevant information and do not require students to look for additional information will not support the development of students' modeling competences and in-depth thinking.

\section{Research questions}

After first investigating what errors Indonesian students make when solving contextbased tasks (Wijaya et al. 2014), and then looking for a possible explanation for these errors by examining the OTL provided by Indonesian textbooks (Wijaya et al. 2015), the present study is researching students' OTL from the perspective of teachers; focusing on teaching practices and related beliefs. Although the main emphasis was on teaching practices, we started with teachers' beliefs, because having beliefs that support using context-based mathematics tasks can be considered necessary for a teaching practice that offers students OTL to solve such tasks. In the study, we addressed the following research questions:

1. What beliefs do Indonesian teachers have regarding teaching and learning of mathematics, and context-based tasks?

2. What OTL to solve context-based tasks do Indonesian teachers offer students in their classroom practice as reflected by (a) the kinds of context-based tasks offered and (b) the teaching approach used by the teachers?

3. Is there a relationship between the OTL to solve context-based tasks offered by Indonesian teachers and the errors Indonesian students make when solving such tasks?

\section{Method}

\section{Design of the study}

To investigate the students' OTL to solve context-based tasks offered by teachers, a teacher survey study was carried out through a written questionnaire and a series of classroom observations. The written questionnaire was used to answer research questions 1 and $2 \mathrm{a}$, whereas the observations were conducted to find an answer to the research question expressed in $2 b$. Finally, to answer the last research question, the results from both sets of data were compared with the findings from our earlier study (Wijaya et al. 2014) in which we identified the kinds of errors Indonesian students made when solving context-based tasks. 


\section{Participants}

The participants of the study were Junior High School mathematics teachers at seven schools in rural and urban areas in the province of Yogyakarta, Indonesia. In these schools, we earlier collected data for investigating students' errors when solving context-based tasks (see Wijaya et al. 2014). In order to make it possible to connect students' errors with students' OTL to solve context-based tasks offered by teachers, we went back to these schools to do the survey and the classroom observations.

All Junior High School mathematics teachers of the participating schools filled in the questionnaire. This resulted in a sample of 27 teachers (14 male and 13 female), including 9 Grade 7 teachers, 12 Grade 8 teachers, and 11 Grade 9 teachers. ${ }^{1}$ The teachers had 2 to 34 years of teaching experience $(M=19, S D=10.02)$. For the classroom observations we asked all Grade 8 teachers $^{2}$ whether they were willing to be observed and video recorded during two mathematics lessons in which they had to address context-based tasks for which we would provide them a set of tasks. In total, 4 of the 12 Grade 8 teachers volunteered. The other teachers either did not feel confident to be observed or argued that spending two lessons on additional tasks would not fit their time schedule. The teachers whose lessons were observed were from three different schools, had moderate to long teaching experience, and all had a Bachelor degree in mathematics education (see Table 1). They also used the same textbook, Matematika (Textbook for Junior High School, Grade VIII: 2A \& 2B).

\section{Teacher questionnaire}

To gather information about teachers' beliefs and teaching practices we developed a written questionnaire, in which we asked teachers to react to statements about teaching and learning mathematics and context-based tasks. The questionnaire contained:(a) four statements regarding teachers' beliefs about teaching and learning of mathematics teaching, (b) five statements addressing teachers' beliefs about context-based tasks, and (c) seven statements on how teachers see their teaching practices related to contextbased tasks (see Appendix).

In the statements S1-S4 that were used for measuring the teachers' beliefs teaching and learning mathematics, we asked the teachers to react to two opposite statements each reflecting one side of the mechanistic versus realistic view on teaching and learning mathematics. This format we derived from a questionnaire developed by Adamson et al. (2002). In the statements S5-S9, the teachers had to indicate how they think about context-based mathematics tasks. In particular, we wanted to know how they think about giving students explicit suggestions about the required mathematical procedures and how they think about the information provided in the tasks. In this set of statements we also included a statement addressing teachers' opinions about the sufficiency of context-based tasks in their textbooks. All five statements in this section used a five-point rating scale. The statements S10-S16 were meant to investigate how

\footnotetext{
${ }^{1}$ The total number is more than 27 because some teachers taught in two grades.

${ }^{2}$ Although Grade 9 students (the 15-year-olds) are the target group of the PISA studies, we did the observations in Grade 8 because that is where the basis for the performance in Grade 9 is laid. Moreover, the schools did not give permission to do observations in Grade 9 classes due to their preparations for the National Exam.
} 
Table 1 Teachers whose lessons were observed

\begin{tabular}{llllll}
\hline Name $^{\mathrm{a}}$ & School & Gender & Age (year) & Teaching experience (year) & Education background \\
\hline Siti & A & Female & 47 & 26 & B.A. (mathematics education) \\
Ihsan & B & Male & 44 & 17 & B.A. (mathematics education) \\
Leni & B & Female & 42 & 17 & B.A. (mathematics education) \\
Ratih & C & Female & 30 & 4 & B.A. (mathematics education)
\end{tabular}

${ }^{\mathrm{a}}$ These names are pseudonyms

the teachers perceived their teaching practices regarding context-based tasks. The statements were about how frequently teachers give and make their own contextbased tasks and how frequently they offer their student context-based tasks with particular characteristics. The teachers were asked to indicate the frequency on a fivepoint rating scale.

\section{Classroom observations}

\section{Procedure}

Classroom observations were conducted to further investigate teachers' teaching practice regarding context-based tasks. We observed two lessons for each of the four Grade 8 teachers who volunteered to participate in this part of the study. Because these classroom observations were intended to investigate how teachers helped their students to learn solving context-based tasks, rather than to examine the frequency of dealing with context-based tasks (this was covered by the questionnaire), we wanted to be sure the teachers would teach context-based tasks in their lessons. Therefore, we provided them with a set of 7 context-based tasks consisting of 12 questions on graphs of linear equations. We chose this topic because it was taught in these schools during the observation period.

Unlike the context-based tasks in Indonesian mathematics textbooks in which mostly camouflage contexts are used with explicit references to solution procedures, we provided the teachers with context-based tasks which had the following characteristics. First, the tasks used contexts that were relevant for students, such as internet fees (see Internet task in Fig. 1) and travelling by bike (see Journey task in Fig. 2). Second, most tasks contained superfluous or missing information, which aimed to offer students

An internet company offers two different programs, i.e. Smile and Shine. Program Smile charges customers 31,500 IDR for monthly fee and 30 IDR/1 Megabyte (MB). Program Shine charges customers 18,000 IDR for monthly fee and 45 IDR/1 MB. The registration fees including the price of modem for both programs are the same, i.e. 300,000 IDR. In January Doni subscribed for program Shine. In May Doni used 550 MB of internet data.

a. How much money should be paid by Doni in May?

Doni's internet usage is increasing. He wonders whether it will be beneficial to change the internet program.

b. Doni's internet usage is increasing, when should he change the internet program?

Fig. 1 Internet task 


\begin{tabular}{|c|c|c|}
\hline \multirow{8}{*}{$\begin{array}{l}\text { Last Saturday, Joni and his friends went biking for } \\
\text { three hours nonstop. } \\
\text { During the journey, Joni frequently checked the } \\
\text { odometer on his bike. The table shows the time } \\
\text { and the distance travelled by Joni and his friends. } \\
\text { a. Estimate how far Joni travelled after: } \\
\text { - a half hour } \\
\text { - two hours } \\
\text { b. Estimate when Joni reached the fastest speed. }\end{array}$} & $\begin{array}{c}\text { Time } \\
\text { (in minutes) }\end{array}$ & $\begin{array}{c}\text { Distance } \\
\text { (in km) }\end{array}$ \\
\hline & 10 & 2.5 \\
\hline & 20 & 6 \\
\hline & 35 & 11 \\
\hline & 60 & 20.5 \\
\hline & 90 & 32 \\
\hline & 110 & 38.5 \\
\hline & 150 & 50 \\
\hline
\end{tabular}

Fig. 2 Journey task

OTL to select relevant information. For example, in the Internet task the relevant information the students have to identify is 18,000 IDR (the monthly fee for the program Shine), 45 IDR (the fee per $1 \mathrm{MB}$ ), and $550 \mathrm{MB}$ (the internet usage in May). The last characteristic of the tasks was that they did not explicitly provide references to the mathematical procedure needed to solve them. For example, to solve Question $b$ in the Internet task the students needed to decide whether making a calculation or drawing a graph would be helpful to find the answer.

To ensure the ownership of the teachers when teaching context-based tasks the teachers could employ their own teaching strategies in the observed lessons. Moreover, they were free to choose which and how many of the provided seven tasks they would use. In addition they could also include other context-based tasks, either from their textbook or designed by themselves. The observations were made by the first author and the lessons were video recorded by using two cameras, a static camera to record whole class activity and a dynamic camera to record the interaction between teacher and particular students.

\section{Data analysis}

In total, we video recorded eight lessons. As the unit of analysis we chose an activitybased chunk of video data. This means that a chunk was not based on a particular time slot but on an activity that was carried out in class. In our study, this was a teaching activity related to a context-based task. Because most tasks consisted of more than one question, we treated an activity related to a question as a unit. Activities related to bare mathematics tasks were excluded from the analysis.

The approach we chose for analyzing the video data units was based on what Erickson (2006) called the part-to-whole deductive approach, which can be used when the analysis has a particular theoretical orientation. As discussed earlier, there is evidence from literature that teaching practices which reflect consultative teaching offer students more OTL to solve context-based tasks than directive teaching approaches. Therefore, we developed a framework for coding teaching practices (see Table 2) which included characteristics of both approaches for all four stages of solving a context-based task. When a teacher did not pay attention to a particular stage, it was coded as "no instruction."

The coding was carried out by the first author and afterwards the reliability of the coding was checked through an additional coding by a researcher of mathematics education not involved in this study. This extra coding was done based on two randomly selected lessons from the eight video-recorded lessons. The Cohen's Kappa for the coding of these two lessons was .89 , which indicates that the coding was reliable (Landis and Koch 1977). 


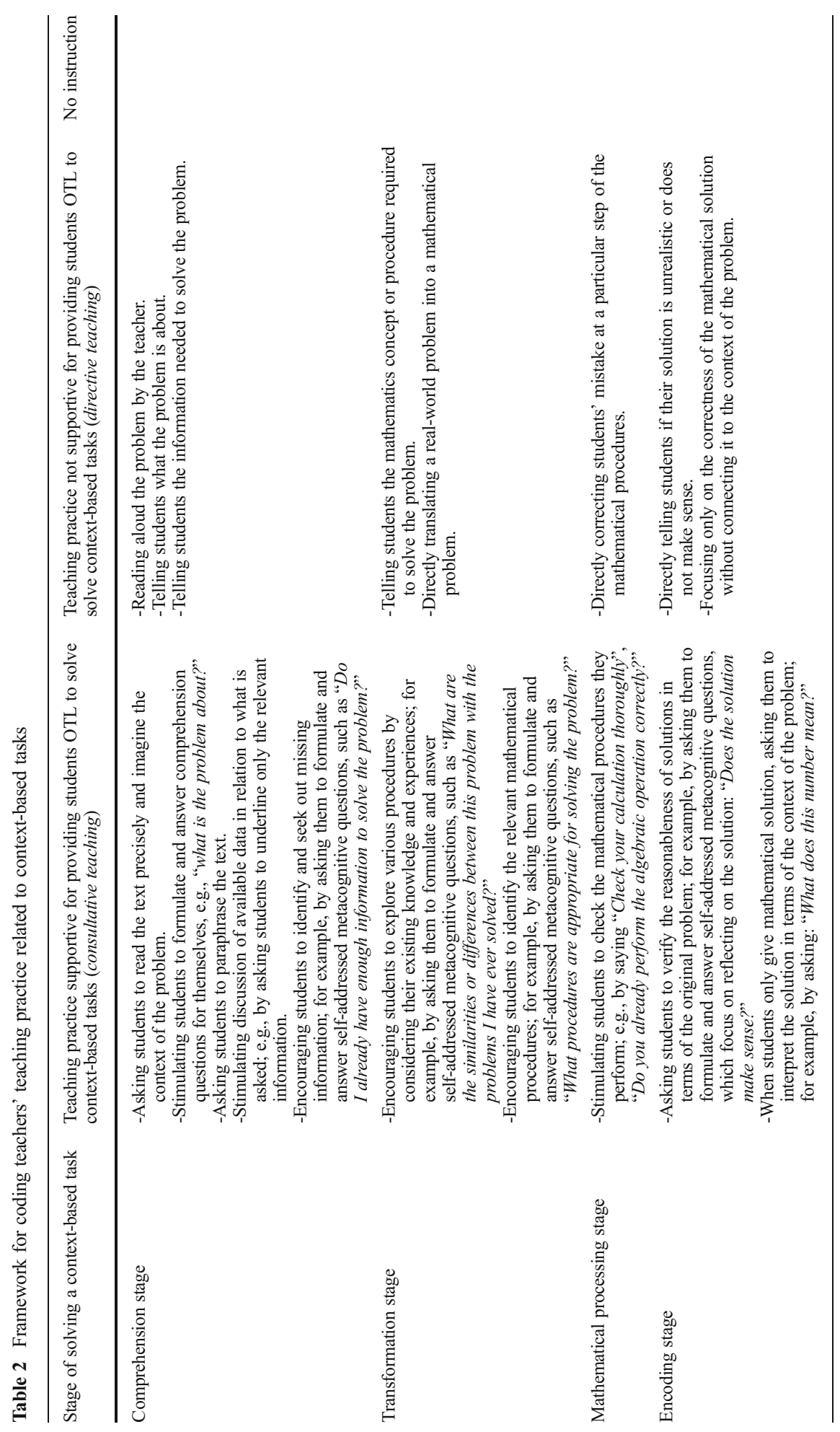




\section{Results}

\section{Teachers' beliefs}

\section{Beliefs about mathematics teaching and learning}

Regarding teachers' beliefs about the teaching and learning of mathematics, the questionnaire data indicate the teachers' tendency toward realistic view (see Fig. 3). When they were asked about their views on teaching mathematics, more than $90 \%$ of the teachers $(25$ out of 27) tended to believe that mathematics teaching should focus on encouraging thinking and reasoning among students and not only on teaching mathematics content. With respect to teachers' beliefs about mathematics learning, we found almost $60 \%$ of the teachers (16 out of 27) tended to believe that students' learning is more likely to occur when students are actively engaged in problems situated in various contexts and more than half of the teachers (15 out of 27) indicated believing that mathematics learning has as an objective to motivate students to learn skills needed in daily life. However, only $26 \%$ of the teachers ( 7 out of 27 ) agreed that school mathematics is about teaching skills that students will need in daily life and almost half (13 out of 27) believed that school mathematics is about teaching pure mathematics. Here, the teachers showed a rather mechanistic view on learning mathematics. Maybe this is elicited by the way the statement was formulated. Different from the other statements that use general terms like "learning" or "teaching," for this statement the rather specific term "school mathematics" was used that might have directed the teachers to reflect on what is currently mandated in the curriculum, rather than on their personal view of what should be taught.

\section{Beliefs about context-based tasks}

Regarding their beliefs about context-based tasks most teachers reflected ideas that are not considered to be supportive for students' learning to solve context-based tasks. Figure 4 shows that three quarters of the teachers (20 out of 27) tended to agree with explicitly providing mathematical procedures in context-based tasks. With respect to the type of information that is included in a task the teachers' beliefs seemed to be more supportive

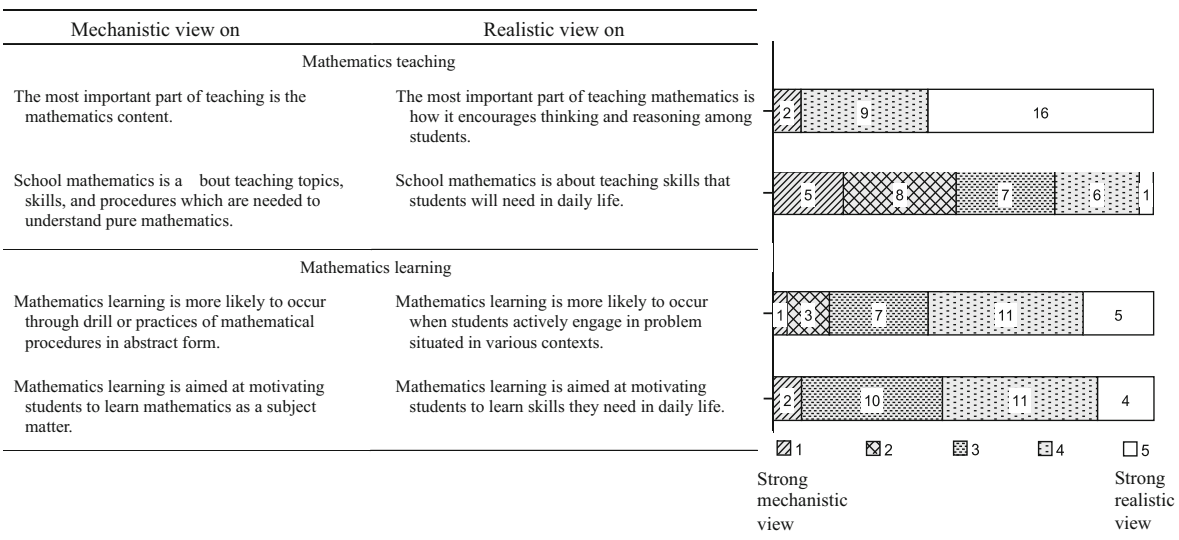

Fig. 3 Teachers' beliefs about mathematics teaching and learning 
Context-based tasks should provide explicit suggestion about the mathematical procedures required to find the solution

Context-based tasks should provide only information which is needed to find the solution

Context-based tasks should also include information that is not needed to find the solution

Context-based tasks should contain less information than what is needed to find the solution

The amount of context-based tasks provided in the textbook(s) that I use is already sufficient

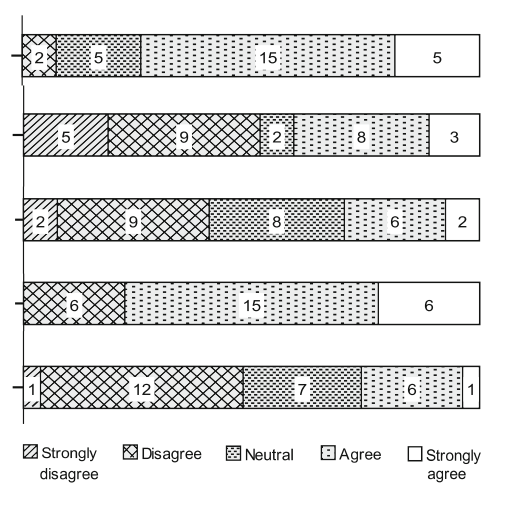

Fig. 4 Teachers' beliefs about context-based tasks

for students' learning to solve context-based tasks. Only $41 \%$ of the teachers (11 out of 27 ) tended to agree to give precisely the information needed to solve a task and half of the teachers (14 out of 27) tended to disagree. Yet teachers were not particularly in favor of including superfluous information; barely $30 \%$ of the teachers (8 out of 27) (strongly) agreed. However, for having less information than needed the situation was different. For this characteristic three quarters of the teachers (21 out of 27) (strongly) agreed.

Finally, we asked whether or not the teachers agreed with the statement that the number of context-based tasks provided in textbooks is sufficient. Almost half (13 out of 27) (strongly) disagreed and only a quarter (7 out of 27) (strongly) agreed.

\section{Teachers' reported teaching practices}

\section{Frequency of offering context-based tasks}

As shown in Fig. 5, according to the teachers' own judgment, they frequently present context-based tasks to their students. $81 \%$ of them (22 out of 27 ) reported giving

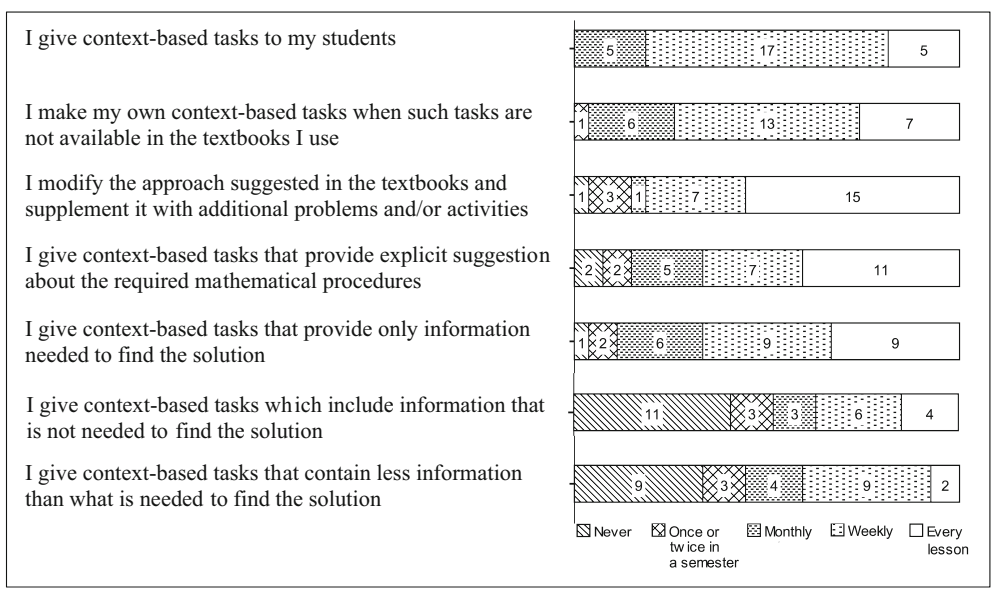

Fig. 5 Teachers' reported teaching practices 
context-based tasks at least weekly. Moreover, three quarters (20 out of 27) stated they make their own context-based tasks at least weekly when such tasks are not available in the textbooks. Regarding modifying the textbook approach and supplementing it with additional problems, $81 \%$ of the teachers (22 out of 27 ) reported doing so at least weekly.

\section{Characteristics of context-based tasks}

Regarding the characteristics of context-based mathematics tasks, the questionnaire data revealed that according to the teachers they mostly present plain word problems (see the last four statements in Fig. 5). Two thirds (18 out of 27) stated they present context-based tasks with explicit suggestions about the mathematical procedures at least weekly. The same result was found for context-based tasks which provide only the information needed to find a solution. Furthermore, $41 \%$ (11 out of 27) reported never giving context-based tasks with superfluous information. Regarding context-based tasks with missing information, $33 \%$ (9 out of 27) reported that they never give such tasks and an equal percentage of the teachers said to give such tasks weekly.

\section{Observed teaching practices}

Table 3 shows the number of cases in which mathematics tasks were dealt with in the eight lessons observed in the four classrooms. Because tasks can consist of one or more questions we took questions as our unit of analysis. Both the bare mathematics questions and the context-based questions can be used as a worked example (a question that is given before an exercise, explaining and demonstrating how to find a solution) or as an exercise (a question to be solved by the students). Unlike worked example questions which are by definition discussed in class, exercise questions are not always discussed with the students.

A total of 29 cases related to a context-based mathematics question were presented to the students, of which 27 involved exercises and 2 involved worked examples. The same number of cases was found for the bare mathematics questions, either designed by the teachers themselves or taken from the textbook. Of these 29 cases, 11 were presented as worked examples. The number of cases in which the teachers gave a context-based mathematics question ranged from 4 in Ratih's classroom, to 13 in

Table 3 Number of cases a mathematics question was presented in the four observed classrooms

\begin{tabular}{|c|c|c|c|c|}
\hline \multirow[t]{2}{*}{ Teacher } & \multicolumn{2}{|c|}{$\begin{array}{l}\text { Number of cases related to a bare mathematics } \\
\text { question }\end{array}$} & \multicolumn{2}{|c|}{$\begin{array}{l}\text { Number of cases related to a context-based } \\
\text { mathematics question }\end{array}$} \\
\hline & Worked example question & Exercise question & Worked example question & Exercise question \\
\hline Siti & 3 & 5 (all discussed) & - & 6 (4 discussed) \\
\hline Ihsan & 2 & 2 (all discussed) & 2 & 11 (6 discussed) \\
\hline Leni & 3 & 6 (4 discussed) & - & 6 (3 discussed) \\
\hline Ratih & 3 & 5 (all discussed) & - & 4 (2 discussed) \\
\hline Total & 11 & 18 (16 discussed) & 2 & 27 (15 discussed $)$ \\
\hline
\end{tabular}


Ihsan's classroom. Ihsan was also the only teacher who included his own context-based mathematics questions. Another observation related to teaching practice is that in only half the cases related to a context-based mathematics question, i.e., 15 cases, the question was discussed in class.

In the following, we describe the observed teaching practice in these 15 cases in more detail. As shown in Fig. 6, to help students learn to solve context-based tasks, the teachers more frequently used a directive than a consultative teaching approach. Directive teaching was mostly used in the comprehension stage, whereas consultative teaching was mostly used in the mathematical processing stage. We also found a substantial number of cases where no instruction was given. This happened in all stages, but most often in the encoding and transformation stages.

\section{Comprehension stage}

In the comprehension stage, attention was paid to 12 of the 15 cases in which a question was discussed in class. All teachers used directive teaching, i.e., reading the tasks aloud and telling students what they were about. Furthermore, no teacher asked students to paraphrase the tasks and explain what they understood from the tasks. For the remaining three cases, the teachers did not discuss what the tasks were about, but directly asked students the mathematical procedure that is required to find the solution. This means the teachers skipped the comprehension stage and directly focused on the transformation stage.

An example of directive teaching in the comprehension stage is when Leni and her students were working on the Journey task (see Fig. 2 and Excerpt 1). After distributing

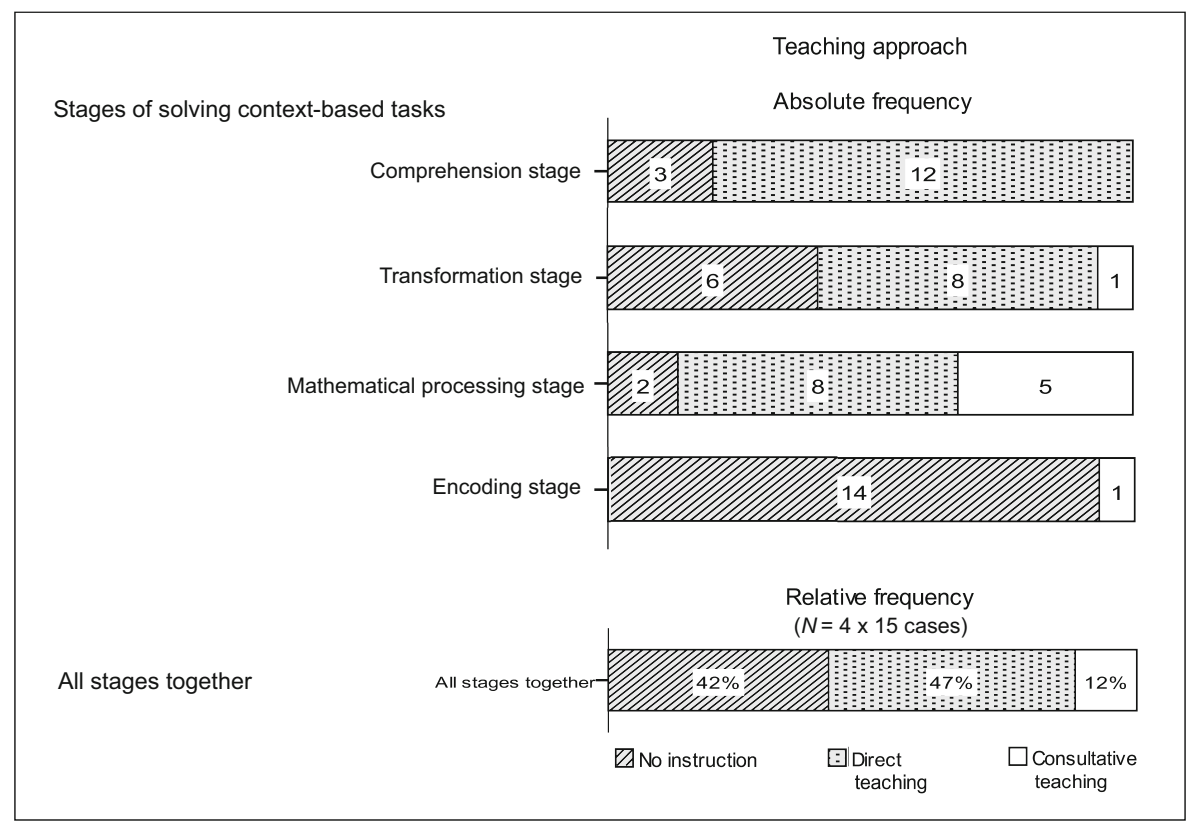

Fig. 6 Overview per stage and over all stages of the teaching approaches used by the 4 teachers in the 15 found cases that were related to a context-based mathematics question 
the student worksheet, Leni directly read aloud the text to her students (see lines 1-4) and demonstrated how to read information in the table (see lines 5-7). The students were not given opportunities to paraphrase the task and to derive information from the table by themselves.

\section{Excerpt 1. Teacher Leni: Journey task}

Leni: For task 2 (the Journey task), I will read it for you. [Reading the text] Last Saturday, Joni and his [1] friends went biking for three hours nonstop. [...] The table shows the time and the distance [2] travelled by Joni and his friends.

[Reading the information in the table] After biking for $10 \mathrm{~min}$, Joni checked his odometer showing [5] $2.5 \mathrm{~km}$. After $20 \mathrm{~min}$, he checked his odometer again which showed $6 \mathrm{~km}$; and so on.

\section{Transformation stage}

In the transformation stage, 9 of the 15 questions were discussed in class. In eight of these questions, directive teaching was observed. For example, Ihsan did not ask his students to interpret the question "if water is poured into the tank in $10 \mathrm{~min}$, how much water is in the tank?" by themselves (see Question $c$ in Fig. 7), but he translated this question into "if the value of $x$ is 10 , then what is the value of $y$ ?" (lines 1-2 in Excerpt 2).

\section{Excerpt 2. Teacher Ihsan: Water tank task, Question c}

Ihsan:

Another kind of directive teaching observed in the transformation stage was telling the students what mathematical procedure to carry out. For example, when Leni and her students discussed a question about estimating the time Joni reached the fastest speed (see Question $b$ in Fig. 2). Although Leni encouraged her students to share their answers (see lines 3 and 5 in Excerpt 3), her focus was on the answers and not on stimulating them to identify relevant mathematical procedures. Furthermore, Leni directly told her students the fastest speed was the steepest line (see lines 5-9).

The water in the backyard is filled in with water every day. The relation between the time of filling water and the volume of water poured into the tank is shown in the table.

a. Let $x$ be the time of filling water and $y$ be the volume of Water poured into the tank. Does every pair of time and the related volume given in the table satisfy the equation $y=5 x+2 ?$

b. Plot the points representing the pairs of $(x, y)$ on the Cartesian coordinate and sketch a graph passing all these points.

\begin{tabular}{|c|c|}
\hline $\begin{array}{c}\text { Time }(x) \\
\text { in minutes }\end{array}$ & $\begin{array}{c}\text { Volume of water } \\
\text { in the tank }(y) \\
\text { in litre }\end{array}$ \\
\hline 0 & 2 \\
\hline 1 & 7 \\
\hline 2 & 12 \\
\hline 3 & 17 \\
\hline 4 & 22 \\
\hline 5 & 27 \\
\hline
\end{tabular}

c. If water is filled into the tank in 10 minutes, how much water is in the tank?

Fig. 7 Water tank task (this task was made by Ihsan) 


\section{Excerpt 3. Teacher Leni; Journey task: Question b}

\begin{tabular}{lll}
\hline Leni: & Now Question $b$. Estimate when Joni reached the fastest speed. & {$[1]$} \\
Student 1: & At (the period of) $60-90$ min. & {$[2]$} \\
Leni: & Any other opinion? & {$[3]$} \\
Student 2: & $110-150$. & {$[4]$} \\
Leni: & Any other (opinion)? ... The fastest speed means that in a short time he (Joni) travelled & {$[5]$} \\
& $\quad$ the furthest distance. Among these lines [pointing at the segments on the graph], & {$[6]$} \\
& $\quad$ this (the fastest speed) is the line (segment) which is the most .... ... The fastest & {$[7]$} \\
& speed is the steepest line. Which is the steepest line? & {$[8]$} \\
& & {$[9]$} \\
\hline
\end{tabular}

In the transformation stage, a consultative teaching approach was observed only in Ihsan's class, when he discussed Question $a$ of the Water tank task (Fig. 7). Ihsan posed questions such as "How do we check it?" and "Which formula?" to stimulate students to think about strategies to solve the task (see line 2 and 5 in Excerpt 4).

\section{Excerpt 4. Teacher Ihsan: Water tank task, Question a}

\begin{tabular}{|c|c|c|}
\hline Ihsan: & $\begin{array}{l}\text { For Question } a \text { you are asked to check whether they (the pairs of values in the table) } \\
\text { satisfy the equation } y=5 x+2 \text {. How do we check it? }\end{array}$ & $\begin{array}{l}{[1]} \\
{[2]}\end{array}$ \\
\hline Students: & (By using) subtraction and addition. & {$[3]$} \\
\hline $\begin{array}{l}\text { Other } \\
\text { students: }\end{array}$ & Using that formula. The formula of $y$. & [4] \\
\hline Ihsan: & Which formula? & {$[5]$} \\
\hline Students: & The formula $y=5 x+2$ & {$[6]$} \\
\hline Ihsan: & Okay. If the $x$ is substituted by 0 , is it correct that $y$ is 2 ? & [7] \\
\hline Students: & Yes, it is. & {$[8]$} \\
\hline Ihsan: & Now, let's try another value $\ldots$ for $x=3$. What is the value of $y$ ? & [9] \\
\hline A student: & $5 \times 3+2 \ldots 18$ (this answer is incorrect; the correct answer is 17 ). & [10] \\
\hline Ihsan: & $\begin{array}{l}\text { [Ignoring the student's answer and directly explaining the steps] Take } x=3 \text {. What is the } \\
\text { formula? } y=5 x+2 \text {. This means [Writing on the board: } y=5 \times 3+2 ; y=17 \text { ]. }\end{array}$ & $\begin{array}{l}{[11]} \\
{[12]} \\
{[13]}\end{array}$ \\
\hline
\end{tabular}

In the transformation stage, it was further observed that when students had already found an adequate transformation into a mathematical problem - which was the case in 6 of the 15 questions - the teachers did not discuss with their students how they arrived at this mathematical problem and whether other procedures would have also been possible.

\section{Mathematical processing stage}

In comparison to the other stages, in the mathematical processing stage a consultative teaching approach was observed more frequently. This means teachers posed questions to engage students in discussing mathematical procedures. Excerpt 4 also illustrates a consultative teaching approach in the mathematical processing stage. In lines 7-13 Ihsan interacts with his students in discussing Question $a$ of the Water tank task 
(Fig. 7). This discussion was about checking whether pairs of values in the table satisfy a given linear equation. In line 7 , the consultative approach is visible when Ihsan engaged his students in the solving process by asking them to check whether the result of the substitution was correct. Furthermore, he encouraged students to do the substitution by themselves (see line 9).

\section{Encoding stage}

Our results clearly revealed that the teachers tended to ignore the encoding stage of solving context-based tasks. They only focused on the correctness of students' mathematical solutions without connecting the answers to the task's context. A consultative approach was observed in only 1 out of 15 cases, i.e., in Ihsan's classroom for Question $c$ of the Water tank task (see Fig. 7). When a student gave a number without any measurement unit, Ihsan asked her "Has this already solved the task?" (see line 2 in Excerpt 5). Contrary to Ihsan's teaching approaches in the other stages for this question, directive teaching was not used in the encoding stage. Here he did not directly tell the students to connect the answer to the context, but stimulated them to reflect on the answer. Furthermore, Ihsan also asked students to explain their opinion (see line 5-6). Moreover, in the end, Ihsan asked his students to conclude the correct answer in terms of the context of the task (see line 10).

\section{Excerpt 5. Teacher Ihsan: Water tank task, Question c}

\begin{tabular}{|c|c|c|}
\hline Ihsan: & $\begin{array}{l}\text { Now let's check Dina's answer. This ... if we substitute } x \text { with } 0 \text { then } y \text { is } 52 \text {. Has this } \\
\text { already solved the task? }\end{array}$ & $\begin{array}{l}{[1]} \\
{[2]}\end{array}$ \\
\hline Student 1: & Yes. & {$[3]$} \\
\hline $\begin{array}{l}\text { Student } 2 \\
\text { and } 3 \text { : }\end{array}$ & Not yet. & {$[4]$} \\
\hline Ihsan & $\begin{array}{l}\text { Some of you said "yes," but some others said "no." Please } \\
\text { explain why this has not yet solved the task. }\end{array}$ & $\begin{array}{l}{[5]} \\
{[6]}\end{array}$ \\
\hline Student 2: & Because there is no "liter" & [7] \\
\hline Ihsan: & Yes, you are right. So, this is $52 \ldots$. what? & {$[8]$} \\
\hline Students: & Liter. & [9] \\
\hline Ihsan: & So, what is the conclusion? & {$[10]$} \\
\hline Students: & The volume of water in the tank is 521 . & {$[11]$} \\
\hline
\end{tabular}

\section{Relation between teachers' beliefs and teaching practices and Students' errors}

Combining the findings of the present study with our earlier findings about the errors Indonesian ninth-graders made when solving context-based tasks (Wijaya et al. 2014), ${ }^{3}$

\footnotetext{
${ }^{3}$ In total, 233 ninth-graders were involved in this previous study that was carried out in school year 20112012. The students came from the same schools as the teachers in the present study which took place in the school year 2012-2013 and involved teachers from Grade 7 to Grade 9. The test that was administered contained 34 questions distributed over four different booklets. Every student made 13 tasks. The analyzed data consisted of 3027 responses (students $\times$ tasks). Of these responses, 1,855 were correct, 346 were missing and 826 were incorrect which included 934 errors (because of the multiple coding, the number of errors is larger than the number of incorrect responses).
} 
we found correspondences between the students' errors and teachers' beliefs and teaching practices regarding context-based tasks.

Table 4 shows that the students made a substantial number of errors in the comprehension stage, which were mostly errors in selecting relevant information. In relation to this earlier finding, $41 \%$ of the teachers tended to agree that contextbased tasks should only provide matching information. Furthermore, a similar percentage of the teachers tended to disagree that superfluous information should be included. Regarding their conceived practice, $67 \%$ of the teachers reported frequently providing context-based tasks with only the information needed to find the solution. Finally, the observed teaching practice revealed that consultative teaching was not used in this stage.

With respect to the transformation stage, our findings were quite similar. For students this is a critical stage, but it turned out that the teachers' beliefs and teaching practices were not so supportive. In this stage students made a high number of errors in identifying the required procedures and, correspondingly, three quarters of teachers tended to agree that context-based tasks should state explicitly the required mathematical procedure. Moreover, two thirds of the teachers indicated frequently offering students such context-based tasks. The observed teaching practice showed that in $40 \%$ of the cases no instruction was given related to this stage and that in half the cases teaching was directive. Hardly any consultative teaching was provided to offer students opportunities to develop their ability in transforming a real-world problem into a mathematical problem.

In the mathematical processing stage, the situation was different. Here consultative teaching was observed in $43 \%$ of the cases, which might also explain why students made fewer mathematical processing errors than comprehension and transformation errors. Lastly, we found that in the encoding stage, where students only made a few errors, in almost all cases the teachers did not give any instruction to students. Obviously, the teachers mostly ignored the interpretation of a mathematical answer in terms of the context of a problem.

\section{Conclusions and discussion}

\section{Teachers' OTL provided to students to solve context-based tasks}

In this study, which is part of the CoMTI project that aims to find possible causes of Indonesian students' difficulties in solving context-based tasks, we examined the OTL to solve context-based tasks which are offered by teachers. Our study focused on teachers' teaching practices and underlying beliefs. Data were collected by a teacher survey based on a written questionnaire and classroom observations.

The first focus of the study was to investigate the Indonesian teachers' beliefs about the nature of mathematics, the teaching and learning of mathematics, and context-based tasks (Research question 1). We found that in general, the Indonesian teachers in our study had a tendency toward a realistic view on teaching and learning mathematics. This indicates the teachers are supportive for offering students OTL to solve contextbased tasks. However, similar to the finding of Beswick's (2005) that an individual teacher's beliefs might not fit neatly in a single category, the teachers in our study were 


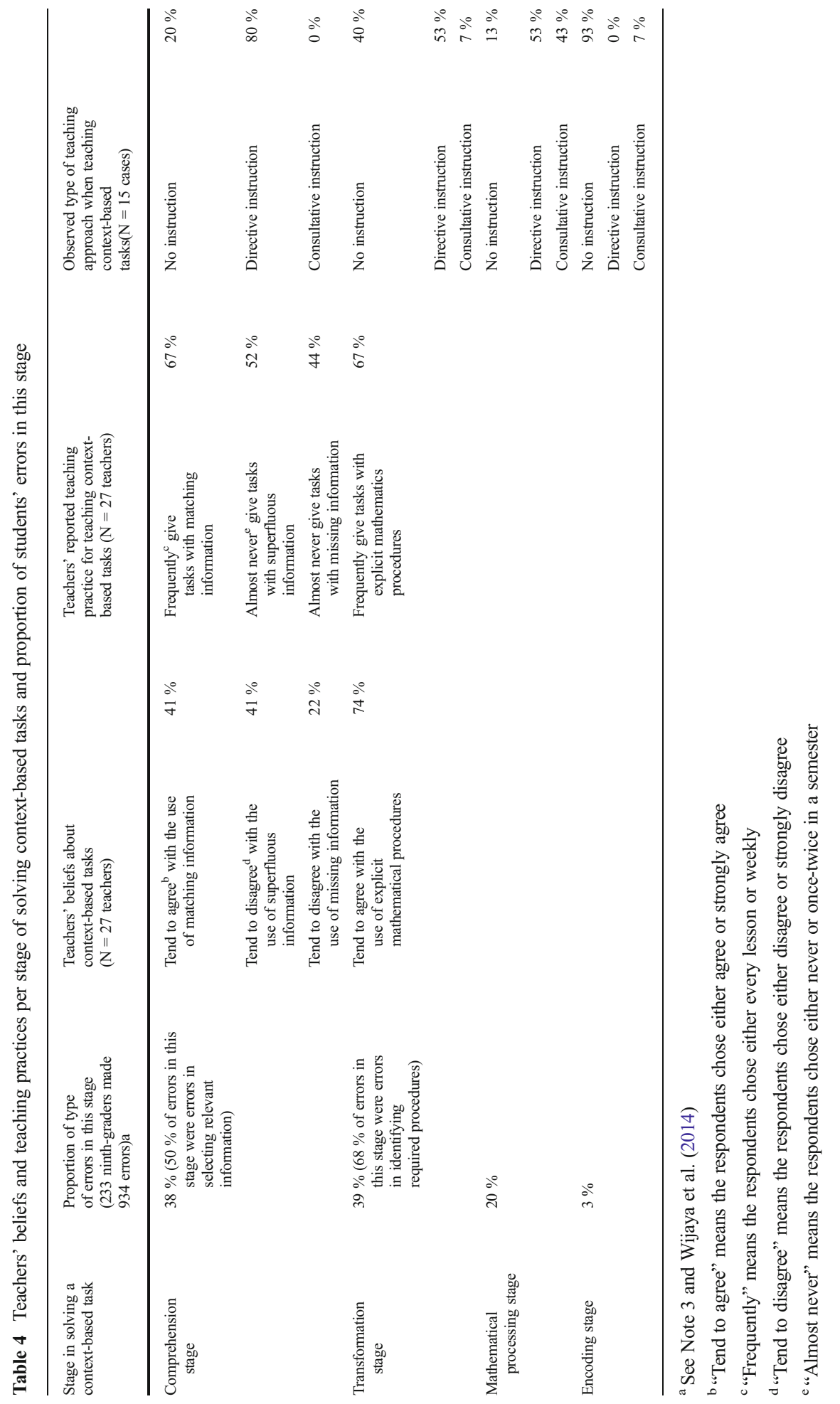


also not always consistent in their responses. Almost half of them believed that school mathematics is teaching pure mathematics, which clearly reflects a mechanistic view.

Regarding the teachers' beliefs about context-based tasks, we found that the teachers tended to perceive context-based tasks as merely plain word problems. Most teachers thought that context-based tasks should provide only the information needed to find the solution and should explicitly provide the required mathematical procedures. In line with other researchers (Chapman 2009; Galbraith and Stillman 2006; Maass 2010; Verschaffel et al. 2010), we argue that having such beliefs about context-based tasks and perceiving context-based tasks as straightforward word problems will not be supportive for providing students OTL to solve context-based tasks. Teachers who have such beliefs might only focus on the mathematical properties or structures of a context-based task without attaching great value to the problems' context (Chapman 2009). Furthermore, they might abandon daily life knowledge and experiences during the solving process (Galbraith and Stillman 2006) and might not contribute to the students' sense-making of a problem (Verschaffel et al. 2010).

When investigating the kinds of context-based tasks the Indonesian teachers offer their students (Research question 2a), the questionnaire data indicated a relation with the teachers' beliefs. In agreement with their beliefs, the teachers reported that they mostly gave context-based tasks which explicitly provide the needed procedures and contain only the information that is relevant for solving the tasks. Furthermore, most teachers stated that they rarely gave context-based tasks with superfluous information.

With respect to how context-based tasks were taught (Research question 2b), the classroom observations revealed that the Indonesian teachers in our sample mainly used a directive teaching approach. The teachers mainly told their students what the problem is about, what information they have to use, and what mathematical problem they have to solve. The teachers also immediately corrected their students' mistakes when performing a mathematical procedure, and focused on the mathematical solution without connecting it to the context of the problem. In agreement with Antonius et al. (2007) who argued that teaching context-based tasks requires more than telling what students should do and offering exercises to practice, we argue that the observed teaching practice in the investigated Indonesian classrooms cannot be considered to be supportive for providing students OTL to solve context-based tasks. More specifically, our observation that in the comprehension stage the teachers did not give their students opportunities to paraphrase the tasks, might contribute to students' difficulty in comprehending a context-based task (see Hagaman et al. 2012). Paraphrasing would help students to understand the text of a task and to get access to what they already know about the task (Kletzien 2009). The directive teaching observed in the transformation stage is also not beneficial to teaching students to solve context-based tasks, because as Barnes (2000) stressed, this teaching discourages students to think about mathematical concepts involved in tasks. Only in the mathematical processing stage did we find the teachers using consultative teaching, which may be so because the teachers have more experience in teaching mathematical procedures than in dealing with real-world problems. Therefore they might have more flexibility in supporting their students' learning in the mathematical processing stage. Lastly, in the encoding stage, the teachers tended to completely ignore the interpretation of mathematical solution(s) in terms of the context of the problem.

Our finding about teachers' preference for the directive teaching approach is in line with results from other studies which also examined teaching practices in mathematics 
classrooms in Indonesia (see, e.g., Human Development Department East Asia and Pacific Region 2010; Maulana et al. 2012). These studies revealed that Indonesian mathematics teachers tended to take a directive role in which they mostly explain while students write, listen, and answer closed questions. Maulana et al. (2012) argued that such directive practices might be caused by a cultural aspect of Indonesian society that considers the teacher profession as highly respected, so the teacher is considered as the source of knowledge, whereas students are the recipients.

Lastly, our study showed a correspondence between the teachers' teaching practices and their related beliefs regarding context-based tasks on the one side, and on the other side the errors which the Indonesian students, involved in our earlier study, made when solving these tasks (Research question 3). The teachers' conceived characteristics of context-based tasks regarding the information included in these tasks and the provision of clear indications for mathematical procedures to be applied are clearly related to the errors students made in the comprehension and transformation stages. Also the teachers' teaching practice regarding context-based tasks possibly explains the high number of comprehension and transformation errors of the students. In other words, our findings at least indicate that the shortage in the OTL to solve context-based tasks, which is offered by the teachers, is a possible explanation for students' difficulties solving these tasks.

\section{Limitations and recommendations}

Since our study has several limitations, our conclusions should be interpreted with caution. First of all, we took results from the PISA studies as the starting point for our project and used PISA tasks to assess students' errors in solving context-based tasks. This is certainly a limitation because the tasks used in PISA cannot be considered the only way of assessing students' ability in applying mathematics and testing students' mathematics-related real-life skills and competencies in solving problems in authentic contexts (see, e.g., Mortimore 2009). Thus, in further research, a broader scope should be taken into account when investigating students' ability to apply mathematics; for example, by using mathematics tasks which require complex modeling. Another limitation of our study is that the data were partly based on self-reports. So teachers' reports about their teaching practices regarding context-based tasks should be considered with prudence. Another limitation is that the classroom observations were only conducted in four classrooms and in each of these classrooms only two lessons were observed. This means that only a snapshot of the teachers' teaching practices was captured. Moreover, in this selection, the focus was only on one mathematics topic. Maybe the teachers would have shown other teaching practices if they were observed for a longer time and the observations also involved other mathematics topics. In any case, a larger sample of teachers would have given a more reliable picture of Indonesian teachers' teaching practices regarding context-based tasks. Finally, to answer the research question about the relationship between OTL offered by the teachers and the errors made by the students, we used data which came from the same schools but not from the same cohorts.

These limitations make it clear that for a more robust understanding of the teachers' role in the difficulties students have with solving context-based tasks, further research, which has a wider scope including more teachers and followed together with their students over a 
longer time, is necessary. Nevertheless, our present study gave us a first understanding of the importance of the OTL to solve context-based tasks offered by teachers and added to our study about this OTL offered by textbooks (Wijaya et al. 2015).

Based on this first understanding, we have the following recommendations for educational practice. When confronted with students' low performance in solving context-based tasks, teachers (and prospective teachers) should look critically at their own role in students' learning processes. Did they really offer their students opportunity-to-learn to solve context-based tasks? And were they aware of the different stages of solving context-based tasks, each requiring specific opportunities to learn?

Acknowledgments This research was supported by the Indonesian Ministry of Education and Culture under the project of Better Education through Reformed Management and Universal Teacher Upgrading (BERMUTU) IDA CREDIT NO.4349-IND, LOAN NO.7476-IND.

\section{Appendix}

Table 5 CoMTI Questionnaire for measuring teachers' beliefs and practice regarding context-based tasks

\begin{tabular}{|c|c|c|c|c|c|c|c|c|c|c|}
\hline \multicolumn{11}{|c|}{ Beliefs about teaching and learning of mathematics } \\
\hline & Statement & \multicolumn{5}{|c|}{$\begin{array}{l}\text { Here you see two opposite statements } \\
\text { Indicate where your position is }\end{array}$} & \multicolumn{4}{|c|}{ Statement } \\
\hline S1 & $\begin{array}{l}\text { The most important part of instruction is the content } \\
\text { of the curriculum. }\end{array}$ & $\square$ & $\square$ & $\square$ & $\square$ & $\square$ & \multicolumn{4}{|c|}{$\begin{array}{l}\text { The most important part of instruction is how it encourages } \\
\text { thinking among students. }\end{array}$} \\
\hline S2 & $\begin{array}{l}\text { School mathematics is about learning skills which are } \\
\text { needed to understand higher levels mathematics }\end{array}$ & $\square$ & $\square$ & $\square$ & $\square$ & $\square$ & \multicolumn{4}{|c|}{$\begin{array}{l}\text { School mathematics is about learning skills that students will } \\
\text { need in daily life. }\end{array}$} \\
\hline S3 & $\begin{array}{l}\text { Mathematics learning is more likely to occur through } \\
\text { drill or practices of mathematical procedures in } \\
\text { abstract or formal forms }\end{array}$ & $\square$ & $\square$ & $\square$ & $\square$ & $\square$ & \multicolumn{4}{|c|}{$\begin{array}{l}\text { Mathematics learning is more likely to occur when students } \\
\text { actively engage in problem situated in various contexts. }\end{array}$} \\
\hline S4 & $\begin{array}{l}\text { Mathematics learning is aimed at motivating students to } \\
\text { learn mathematics as a subject matter }\end{array}$ & $\square$ & $\square$ & $\square$ & $\square$ & $\square$ & \multicolumn{4}{|c|}{$\begin{array}{l}\text { Mathematics learning is aimed at motivating students to learn } \\
\text { skills they need in daily life. }\end{array}$} \\
\hline \multicolumn{11}{|c|}{ Beliefs about context-based tasks } \\
\hline & \multicolumn{3}{|l|}{ Statement } & \multicolumn{2}{|c|}{$\begin{array}{l}\text { Strongly } \\
\text { disagree }\end{array}$} & \multicolumn{2}{|r|}{ Disagree } & Neutral & Agree & $\begin{array}{l}\text { Strongly } \\
\text { Agree }\end{array}$ \\
\hline S5 & \multicolumn{3}{|c|}{$\begin{array}{l}\text { Context-based tasks should provide explicit suggestion about the } \\
\text { mathematical procedures required to find the solution. }\end{array}$} & \multicolumn{2}{|c|}{$\square$} & \multicolumn{2}{|r|}{$\square$} & $\square$ & $\square$ & $\square$ \\
\hline S6 & \multicolumn{3}{|c|}{$\begin{array}{l}\text { Context-based tasks should provide only information which is needed } \\
\text { to find the solution. }\end{array}$} & \multicolumn{2}{|c|}{$\square$} & & $\square$ & $\square$ & $\square$ & $\square$ \\
\hline S7 & \multicolumn{3}{|c|}{$\begin{array}{l}\text { Context-based tasks should also include information that is not needed } \\
\text { to find the solution. }\end{array}$} & \multicolumn{2}{|c|}{$\square$} & & $\square$ & $\square$ & $\square$ & $\square$ \\
\hline S8 & \multicolumn{3}{|c|}{$\begin{array}{l}\text { Context-based tasks should contain less information than what is } \\
\text { needed to find the solution. }\end{array}$} & \multicolumn{2}{|c|}{$\square$} & & $\square$ & $\square$ & $\square$ & $\square$ \\
\hline S9 & \multicolumn{3}{|c|}{$\begin{array}{l}\text { The amount of context-based tasks provided in the textbook(s) that I } \\
\text { use is already sufficient }\end{array}$} & \multicolumn{2}{|c|}{$\square$} & & $\square$ & $\square$ & $\square$ & $\square$ \\
\hline \multicolumn{11}{|c|}{ Teaching practices regarding context-based tasks } \\
\hline & \multicolumn{3}{|l|}{ Statement } & \multicolumn{2}{|c|}{ Every lesson } & \multicolumn{2}{|c|}{ Weekly } & Monthly & $\begin{array}{l}\text { Once or twice } \\
\text { a semester }\end{array}$ & Never \\
\hline S10 & \multicolumn{3}{|l|}{ I give context-based tasks to my students. } & \multicolumn{2}{|c|}{$\square$} & & $\square$ & $\square$ & $\square$ & $\square$ \\
\hline S11 & \multicolumn{3}{|c|}{$\begin{array}{l}\text { I make my own context-based tasks when such tasks are not available in the } \\
\text { textbook I use. }\end{array}$} & \multicolumn{2}{|c|}{$\square$} & & $\square$ & $\square$ & $\square$ & $\square$ \\
\hline S12 & \multicolumn{3}{|c|}{$\begin{array}{l}\text { I modify the approach suggested in the textbooks and supplement it } \\
\text { with additional problems and/or activities. }\end{array}$} & \multicolumn{2}{|c|}{$\square$} & & $\square$ & $\square$ & $\square$ & $\square$ \\
\hline S13 & \multicolumn{3}{|c|}{$\begin{array}{l}\text { I give context-based tasks that provide explicit suggestion about the } \\
\text { required mathematical procedures. }\end{array}$} & $\square$ & & & $\square$ & $\square$ & $\square$ & $\square$ \\
\hline S14 & $\begin{array}{l}\text { I give context-based tasks that provide only informatic } \\
\text { the solution. }\end{array}$ & needed & find & 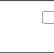 & & & $\square$ & $\square$ & $\square$ & $\square$ \\
\hline S15 & $\begin{array}{l}\text { I give context-based tasks which include informat } \\
\text { needed to find the solution. }\end{array}$ & that & not & $\square$ & & & $\square$ & $\square$ & $\square$ & $\square$ \\
\hline S16 & $\begin{array}{l}\text { I give context-based tasks that contain less informati } \\
\text { needed to find the solution. }\end{array}$ & than & at is & 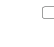 & & & $\square$ & $\square$ & $\square$ & $\square$ \\
\hline
\end{tabular}




\section{References}

Adamson, S., Burtch, M., Cox, T., Banks, D., Judson, E., \& Lawson, T. (2002). Nature of mathematics survey. Paper presented at the 28th AMATYC Annual Conference, Phoenix, Arizona, USA,November 14-17, 2002.

Antonius, S., Haines, C., Jensen, T. H., Niss, M., \& Burkhardt, H. (2007). Classroom activities and the teacher. In W. Blum, P. L. Galbraith, H.-W. Henn, \& M. Niss (Eds.), Modelling and applications in mathematics education (pp. 295-308). New York: Springer.

Barnes, M. (2000). 'Magical' moments in mathematics: insights into the process of coming to know. For the Learning of Mathematics, 20(1), 33-43.

Bell, C. V., \& Pape, S. J. (2012). Scaffolding students' opportunities to learn mathematics through social interactions. Mathematics Education Research Journal, 24(4), 423-445.

Beswick, K. (2005). The beliefs/practice connection in broadly defined contexts. Mathematics Education Research Journal, 17(2), 39-68.

Blum, W. (2011). Can modelling be taught and learnt? Some answers from empirical research. In G. Kaiser, W. Blum, R. B. Ferri, \& G. Stillman (Eds.), Trends in teaching and learning of mathematical modelling (pp. 15-30). New York: Springer.

Blum, W., \& Ferri, R. B. (2009). Mathematical modelling: can it be taught and learnt? Journal of Mathematical Modelling and Application, 1(1), 45-58.

Blum, W., \& Leiss, D. (2007). How do students and teachers deal with mathematical modelling problems? The example "Sugarloaf". In C. Haines, P. Galbraith, W. Blum, \& S. Khan (Eds.), Mathematical modelling (ICTMA 12): education, engineering and economics (pp. 222-231). Chichester: Horwood Publishing.

Brewer, D. J., \& Stasz, C. (1996). Enhancing opportunity to learn measures in NCES data. In G. Hoachlander, J. E. Griffith, \& J. H. Ralph (Eds.), From data to information: new directions for the National Center for Education Statistics (pp. 3.1-3.28). Washington: U.S. Department of Education.

Chapman, O. (2009). Teachers' conceptions and use of mathematical contextual problems in Canada. In L. Verschaffel, B. Greer, W. Van Dooren, \& S. Mukhopadhyay (Eds.), Words and worlds. Modelling verbal descriptions of situations (pp. 227-244). Rotterdam: Sense Publishers.

Clements, M. A. (1980). Analyzing children's errors on written mathematical task. Educational Studies in Mathematics, 11(1), 1-21.

Cooper, B., \& Dunne, M. (2000). Assessing children's mathematical knowledge: social class, sex and problem-solving. Buckingham: Open University Press.

Council, N. R. (2001). Adding it up: helping children learn mathematics. Washington: National Academy Press.

Erickson, F. (2006). Definition and analysis of data from videotape: some research procedures and their rationales. In J. L. Green, G. Camili, \& P. B. Ellmore (Eds.), Handbook of complementary methods in education research (pp. 177-192). Mahwah: Lawrence Erlbaum.

Ernest, P. (1989). The impacts of beliefs on the teaching of mathematics. In P. Ernest (Ed.), Mathematics Teaching: the state of the art (pp. 249-253). New York: Falmer.

Eurydice. (2011). Mathematics education in Europe: common challenges and national policies. Brussels: Education, Audiovisual and Culture Executive Agency.

Forman, S. L., \& Steen, L. A. (2001). Why math? Applications in science, engineering, and technological programs. Research Brief, American Association of Community Colleges.

Galbraith, P., \& Stillman, G. (2006). A framework for identifying student blockages during transitions in the modelling process. ZDM The International Journal on Mathematics Education, 38(2), 143-162.

Gellert, U., \& Jablonka, E. (2009). "I am not talking about reality": word problems and the intricacies of producing legitimate text. In L. Verschaffel, B. Greer, W. Van Dooren, \& S. Mukhopadhyay (Eds.), Words and worlds. Modelling verbal descriptions of situations (pp. 39-53). Rotterdam: Sense Publishers.

Graumann, G. (2011). Mathematics for problem in the everyday world. In J. Maasz \& J. O’Donoghue (Eds.), Real-world problems for secondary school mathematics students: case studies (pp. 113-122). Rotterdam: Sense Publishers.

Grouws, D. A., \& Cebulla, K. J. (2000). Improving student achievement in mathematics. Brussels: International Academy of Education.

Hagaman, J. L., Casey, K. J., \& Reid, R. (2012). The effects of the paraphrasing strategy on the reading comprehension of young students. Remedial and Special Education, 33(2), 110-123. 
Hiebert, J., \& Grouws, D. A. (2007). The effects of classroom mathematics teaching on students' learning. In F. Lester (Ed.), Second handbook of research on mathematics teaching and learning (pp. 371-404). Charlotte: Information Age Publishing.

Human Development Department East Asia and Pacific Region. (2010). Inside Indonesia's mathematics classrooms: a TIMSS Video Study of teaching and practices and student achievement. Jakarta: The World Bank.

Husén, T. (Ed.). (1967). International study of achievement in mathematics: a comparison of twelve countries (Vol. II). New York: Wiley.

Karbalei, A., \& Amoli, F. A. (2011). The effect of paraphrasing strategy training on the reading comprehension of college students at the undergraduate level. Asian EFL Journal, 13(3), 229-344.

Kletzien, S. B. (2009). Paraphrasing: an effective comprehension strategy. The Reading Teacher, 63(1), 73-77.

Kramarski, B., Mevarech, Z. R., \& Arami, M. (2002). The effects of metacognitive instruction on solving mathematical authentic tasks. Educational Studies in Mathematics, 49(2), 225-250.

Landis, J. R., \& Koch, G. G. (1977). The measurement of observer agreement for categorical data. Biometrics, 33(1), 159-174.

Lingefjärd, T., \& Meier, S. (2010). Teachers as managers of the modelling process. Mathematics Education Research Journal, 22(2), 92-107.

Maass, K. (2010). Classification scheme for modelling tasks. Journal für Mathematik-Didaktik, 31(2), 285311.

Maulana, R., Opdenakker, M.-C., Den Brok, P., \& Bosker. (2012). Teacher-student interpersonal behavior in secondary mathematics classes in Indonesia. International Journal of Science and Mathematics Education, 10(1), 21-47.

Mortimore, P. (2009). Alternative models for analysing and representing countries' performance in PISA. A paper commisioned by Education International Research Institute. http://eiie.org/docs/webdepot/ alternativemodelsinpisa.pdf. Retrieved in June 1, 2013

NCTM. (2000). Principles and Standard for School Mathematics. Reston: the NCTM.

Newman, M. A. (1977). An analysis of sixth-grade pupils' errors on written mathematical tasks. Victorian Institute for Educational Research Bulletin, 39, 31-43.

OECD. (2003). The PISA 2003 Assessment Framework - Mathematics, Reading, Science, and Problem Solving Knowledge and Skills. Paris: OECD.

OECD. (2010). PISA 2009 results: What students know and can do. Student performance in reading, mathematics, and science (Vo. I). Paris: OECD.

OECD. (2013). PISA 2012 results: What students know and can do. Student performance in mathematics, reading and science (Vol. I). Paris: OECD.

Prakitipong, N., \& Nakamura, S. (2006). Analysis of mathematics performance of grade five students in Thailand using Newman procedure. Journal of International Cooperation in Education, 9(1), 111-122.

Pusat Kurikulum. (2003). Kurikulum 2004. Standar kompetensi mata pelajaran matematika Sekolah Menengah Pertama dan Madrasah Tsanawiyah [The Curriculum 2004. The standard competences for Junior High School mathematics]. Jakarta: Departemen Pendidikan Nasional.

Sam, L. C., Lourdusamy, A., \& Ghazali, M. (2001). Factors affecting students' abilities to solve operational and word problems in mathematics. Journal of Science and Mathematics Education in Southeast Asia, 24(1), 84-95.

Sepeng, P. (2013). Use of unrealistic contexts and meaning in word problem solving: a case of second language learners in Township schools. International Journal of Research in Mathematics, 1(1), 8-14.

Stipek, D. J., Givvin, K. B., Salmon, J. M., \& MacGyvers, V. L. (2001). Teachers' beliefs and practices related to mathematics instruction. Teaching and Teacher Education, 17(2), 213-226.

Tornroos, J. (2005). Mathematics textbooks, opportunity to learn and student achievement. Studies in Educational Evaluation, 31(4), 315-327.

Treffers, A. (1987). Three Dimensions. A model of goal and theory description in mathematics instructionThe Wiskobas Project. Dordrecht: Reidel Publishing Company.

Valverde, G. A., Bianchi, L. J., Wolfe, R. G., Schmidt, W. H., \& Houang, R. T. (2002). According to the book: using TIMSS to investigate the translation of policy into practice through the world of textbooks. Dordrecht: Kluwer Academic Publishers.

Van den Heuvel-Panhuizen, M. (2010). Reform under attack - forty years of working on better mathematics education thrown on the scrapheap? No Way! In L. Sparrow, B. Kissane, \& C. Hurst (Eds.), Shaping the future of mathematics education: proceedings of the 33rd annual conference of the Mathematics Education Research Group of Australasia. MERGA: Fremantle.

Van den Heuvel-Panhuizen, M., \& Drijvers, P. (2014). Realistic Mathematics Education. In S. Lerman (Ed.), Encyclopedia of Mathematics Education (pp. 521-525). Dordrecht: Springer. 
Verschaffel, L., Greer, B., \& De Corte, E. (2000). Making Sense of Word Problems. Lisse: Swets \& Zeitlinger. Verschaffel, L., Van Dooren, W., Greer, B., \& Mukhopadhyay, S. (2010). Reconceptualising word problem as exercises in mathematical modelling. Journal für Mathematik-Didaktik, 31(1), 9-29.

Wijaya, A., Van den Heuvel-Panhuizen, M., Doorman, M., \& Robitzsch, A. (2014). Difficulties in solving context-based PISA mathematics tasks: an analysis of students' errors. The Mathematics Enthusiast, 11(3), 541-554.

Wijaya, A., Van den Heuvel-Panhuizen, M., \& Doorman, M. (2015). Opportunity-to-learn context-based tasks provided by mathematics textbooks. Educational Studies in Mathematics, 89(1), 41-65.

Wilkins, J. L. M. (2008). The relationship among elementary teachers' content knowledge, attitudes, beliefs, and practices. Journal of Mathematics Teacher Education, 11(2), 139-164.

Xin, Z., Lin, C., Zhang, L., \& Yan, R. (2007). The performance of Chinese primary school students on realistic arithmetic word problems. Educational Psychology in Practice, 23(2), 145-159. 